\title{
Corrosion inhibitor binding in an acidic medium: Interaction of 2- mercaptobenizmidazole with carbon-steel in hydrochloric acid
}

\author{
P. Morales-Gil ${ }^{1}$, M.S. Walczak ${ }^{1}$, R.A. Cottis ${ }^{1}$, J.M. Romero $^{2}$, R. Lindsay ${ }^{1}{ }^{*}$ \\ ${ }^{1}$ Corrosion and Protection Centre, School of Materials, The University of Manchester, Sackville \\ Street, Manchester, M13 9PL, UK \\ ${ }^{2}$ Coordinación Tecnológica de Ingeniería de Corrosión y Producción, Dirección de \\ Exploración y Producción, Instituto Mexicano del Petróleo, Eje Central Lázaro \\ Cárdenas Norte 152, CP 07730, DF, México.
}

*Corresponding author: Robert Lindsay;

Tel: +44 161306 4824;

Fax: +44 161306 486;

email: robert.lindsay@manchester.ac.uk 


\begin{abstract}
Mechanistic understanding of the functionality of organic corrosion inhibitors in acidic media is essential to knowledge-based performance optimization. In this study, we address a key issue hindering progress in this area, namely the chemical nature of the corrosion inhibitor/substrate interface. X-ray photoelectron spectroscopy (XPS) is employed to reveal the surface termination of carbon-steel, following immersion in $1 \mathrm{M}$ hydrochloric acid inhibited with 2mercaptobenzimidazole (MBI). Core level spectra indicate that the termination varies as a function of MBI concentration, with the interface consisting of MBI bound to film-free carbon-steel on highly inhibited substrates.
\end{abstract}

Keywords: Acid solutions (A); Carbon steel (A); XPS (B); Acid inhibition (C) 


\section{Introduction}

For more than a century, corrosion inhibitors have been added to aggressive environments to protect metallic materials [1]. Nevertheless, there are still considerable gaps in fundamental knowledge of corrosion inhibitor (CI) functionality, severely restricting rational development [27]. One outstanding issue is the precise nature of the interfaces formed by inhibitive organic species in corrosive acidic solutions, which are widely encountered in engineering applications, e.g. chemical processing and oil production. It is generally accepted that inhibition in this environment is normally achieved by formation of an adsorbed 2D layer [2], but rudimentary details key to mechanistic understanding remain speculative, including the nature of the organic$\mathrm{CI} /$ substrate interface. Recent experimental evidence suggests that a surface oxide, hydroxide or salt film may facilitate corrosion inhibitor binding [8-10], although direct attachment to the metallic substrate is implicitly assumed in other contemporary work [3,6,7]. Here, we employ X-ray photoelectron spectroscopy (XPS) to provide direct experimental evidence of the latter scenario, i.e. organic species can inhibit corrosion through binding to film-free substrate.

A variety of factors determine the functionality of organic compounds as corrosion inhibitors, with one of the most important being the strength of substrate binding [1,2]. Stronger interfacial bonding largely equates to increased inhibition efficiency, and is therefore a desirable goal of corrosion inhibitor optimisation. On this basis, significant effort is directed towards predicting this interaction through theoretical modeling [5-7,11-15]. To date, however, the vast majority of such work has been concerned solely with calculating supposedly relevant organic-CI characteristics, with no consideration of the substrate (see, for example, [11] and refs. therein, and $[12,13])$. In terms of predictive power, such an approach has at best limited value, and is potentially simply misleading. Attempting to overcome this shortcoming, some theoretical studies have explicitly incorporated organic-CI/substrate bonding into their modelling e.g. [5$7,14,15]$. Such studies are much more likely to deliver valid predictions, although a lack of 
reliable experimental input data (e.g. nature of the organic-CI/substrate interface) hinders their applicability.

In this study, XPS is employed to reveal the interface formed between an organic-CI, 2mercaptobenzimidazole (MBI), and carbon-steel in $1 \mathrm{M}$ hydrochloric acid; complementary electrochemical measurements are undertaken to evaluate the performance of MBI as a corrosion inhibitor under the prevailing conditions. Motivation for selecting this specific system is that the effectiveness of $\mathrm{MBI}$ as a corrosion inhibitor for carbon-steel in acidic environments has already been proven by means of both gravimetric and electrochemical studies [16-22]. Most pertinently, it has been determined that MBI significantly inhibits the corrosion of carbon steel in $1 \mathrm{M} \mathrm{HCl}[16,18,20,21,22]$. In this medium, it is concluded that MBI acts by binding to the carbon-steel substrate, and thermodynamic parameters governing this process (e.g. free energy of adsorption) have been estimated. Furthermore, it is reported that $\mathrm{MBI}$ behaves as a mixed inhibitor, i.e. both the rate of the anodic ( $\mathrm{Fe}^{0}$ oxidation) and cathodic $\left(\mathrm{H}^{+}\right.$reduction) reactions are reduced. These previous studies $[16,18,20,21,22]$, however, do not provide any insight into the chemical nature of the $\mathrm{MBI} /$ carbon-steel interface, which is the goal of this study.

\section{Materials and methods}

Cylindrical carbon-steel rod (10 mm diameter), possessing a nominal weight \% composition (as specified by the supplier, RS Components) of C (0.08 - 0.13), Mn (0.30 - 0.50), P (0.04), S (0.05), and Fe (balance), was employed for both electrochemical and XPS studies. For the former measurements, samples were mounted in epoxy resin (exposed area $0.79 \mathrm{~cm}^{2}$ ), ground with a series of $\mathrm{SiC}$ papers (250 grit, 400 grit, 600 grit, 800 grit) washed with ethanol and deionized water, and dried in a flow of air. As regards XPS, samples again underwent grinding with $\mathrm{SiC}$ papers (600 grit, 800 grit, 1200 grit, 2400 grit, 4000 grit), and were then polished with 
either alumina powder or diamond paste $(3 \mu \mathrm{m}$, and $1 \mu \mathrm{m})$ until a mirror finish was obtained. Subsequently, they were washed with acetone and de-ionized water, and dried. $1 \mathrm{M}$ $\mathrm{HCl}$, prepared by diluting $10.2 \mathrm{M} \mathrm{HCl}$ with deonised water, served as the corrosive medium, with appropriate quantities of MBI (98\% purity, Arcos Organics) added to achieve the required series of concentrations up to $2 \mathrm{mM}$.

Corrosion rates, and hence inhibition efficiencies (see below for definition), were determined by means of linear polarisation resistance (LPR) measurements [23]. These data were acquired in a $1 \mathrm{~L}$ glass cell, using a typical three-electrode arrangement comprising the working electrode (carbon steel), platinum counter electrode, and saturated calomel electrode (SCE) as reference electrode; the latter was located in a separate vessel connected to the primary cell by means of a Luggin probe. A computer-controlled potentiostat (ACM Gill AC 930) was used to acquire the LPR data, employing a sweep rate of $10 \mathrm{mV} / \mathrm{min}$.

XPS was performed in a Kratos Axis Ultra facility (base pressure $\sim 2 \times 10^{-9}$ mbar), equipped with a glove box/load lock system for sample introduction. Samples for XPS analysis were immersed in solution inside the $\mathrm{N}_{2}$-purged glove box, and subsequently removed and inserted directly into the XPS instrument. This approach circumvents exposure to the ambient laboratory atmosphere, avoiding likely post immersion substrate oxidation. It should be noted that upon removal of a sample from solution, it was blown-dry with a stream of nitrogen to prevent evaporation and subsequent physical deposition of solution components onto the sample surface.

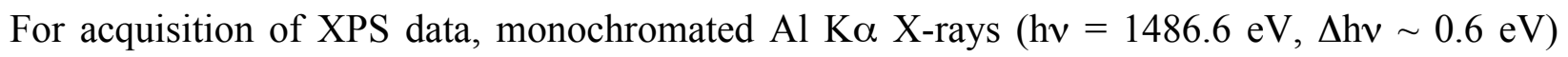
were employed as the photon source. Emitted photoelectrons were collected using a $165 \mathrm{~mm}$ hemispherical energy analyser incorporating a delay line detection system (analysis area $\sim 3 \mathrm{~mm}$ x $2 \mathrm{~mm}$, using electrostatic lens mode). Data were acquired at an analyser pass energy of $20 \mathrm{eV}$. Two photoelectron emission angles $\left(\theta_{\mathrm{E}}\right)$, namely $0^{\circ}$ (emission along the surface normal) and $50^{\circ}$, were utilised during the measurements. The angle subtended by the X-ray beam and the entrance 
lens of the analyser was $60^{\circ}$, and the sample holder's rotation axis was perpendicular to the plane containing these two elements. To prevent any vertical differential charging due to the presence of oxide surface films, samples were mounted using vacuum compatible double-sided adhesive tape. Charge accumulation during data collection was compensated by exposing samples to a flood of low energy electrons $(\leq 3 \mathrm{eV})$. BEs were calibrated by assigning a BE value of $285 \mathrm{eV}$ to the $\mathrm{C} 1 \mathrm{~s}$ hydrocarbon component of adsorbed adventitious carbon [24].

Fitting of XPS profiles was undertaken with CasaXPS software [25]. Gaussian-Lorentzian (GL) line shape functions ( $30 \%$ Lorentzian) were employed to model all of the photoelectron peaks except for the Fe $2 p$ level of metallic iron, where a Lorentzian asymmetric line shape with tail damping (LF) was used. In accord with previous work, only the Fe $2 p_{3 / 2}$ component of the Fe $2 p$ spectra was fitted [24]. For fitting of $\mathrm{Fe}^{2+}$ and $\mathrm{Fe}^{3+}$ states, multiplet envelopes consisting of 3 and 4 GL functions, respectively, and two broader GL functions for satellite peaks have been employed $[24,26]$. Inelastically scattered background electrons were described with a Shirleytype function [27].

\section{Results and Discussion}

To demonstrate the functionality of MBI under the conditions prevailing in this study, the corrosion inhibition efficiency $(\eta \%)$ of this species for carbon-steel in $1 \mathrm{M} \mathrm{HCl}(4 \mathrm{hr}$ of immersion) is plotted as a function of its concentration in bulk solution in Figure 1. $\eta \%$ is defined as:

$\eta \%=\frac{(\mathrm{U}-\mathrm{I})}{\mathrm{U}} \times 100 ;$ 
$\mathrm{U}$ (I) is the uninhibited (inhibited) corrosion rate. As is typical for such systems [2], the corrosion inhibition efficiency of MBI increases asymptotically with its concentration in bulk solution. Moreover, in agreement with previous studies of the corrosion inhibition performance of MBI in acidic solution [16-22], these data indicate that it is a very effective corrosion inhibitor; corrosion rate is reduced from $\sim 27 \mathrm{~mm} /$ year to $\sim 0.4 \mathrm{~mm} /$ year (IE $\sim 99 \%$ ) for the largest MBI concentration (2 $\mathrm{mM})$ studied.

Concerning the chemical composition of the inhibited interfaces, Figure 2 depicts XPS spectra of the $\mathrm{N} 1 \mathrm{~s}, \mathrm{O} 1 \mathrm{~s}, \mathrm{Fe} 2 \mathrm{p}$, and $\mathrm{Cl} 2 \mathrm{p}$ core levels acquired from carbon-steel samples subsequent to immersion in $1 \mathrm{M} \mathrm{HCl}$ with various concentrations of $\mathrm{MBI}$ added $(0 \mathrm{mM}-2 \mathrm{mM})$. Spectra from a polished sample are also shown. Focusing on the $\mathrm{N}$ 1s spectra (Figure 2 (a)), it is clear that significant intensity is obtained only once the carbon-steel has been exposed to MBI, which then increases with MBI concentration. Fitting of these data reveals three peaks, labeled $\mathrm{N}^{1}, \mathrm{~N}^{2}$, and $\mathrm{N}^{3}$. Most simply, the two most intense peaks, $\mathrm{N}^{1}$ and $\mathrm{N}^{2}$, located at binding energies (BE) of $399.0 \mathrm{eV}$ and $\sim 400.6 \mathrm{eV}$ can be assigned, respectively, to the two chemically distinct nitrogen atoms (i.e. pyridine-like and pyrrole-like) present in MBI [28-30]. Figure 3 depicts the molecular structure of MBI, which can exist in two tautomeric forms, thiol and thione, with the nitrogen atoms labelled; $\mathrm{N}^{1}$ (pyridine-like) only appears in the thiol tautomer, $\mathrm{N}^{2}$ (pyrrole-like) appears in both the thiol and thione forms. From the relative intensities of the two features, $\mathrm{I}\left(\mathrm{N}^{2}\right) / \mathrm{I}\left(\mathrm{N}^{1}\right)>1$, it is concluded that $\mathrm{MBI}$ is adsorbed onto the carbon-steel in both of its tautomeric forms. Adsorption of the thiol or thione tautomers alone would lead to $\mathrm{I}\left(\mathrm{N}^{2}\right) / \mathrm{I}\left(\mathrm{N}^{1}\right)$ tending to 1 or $\infty$, respectively.

Assignment of the third smaller $\mathrm{N}$ 1s peak $\left(\mathrm{N}^{3}\right)$, located at $\mathrm{BE} \sim 402.1 \mathrm{eV}$, is more speculative, as its intensity is apparently largely independent of the concentration of MBI in bulk solution. The $\mathrm{BE}$ is consistent with a protonated $\mathrm{N}$ [31], and so it may be the result of a minority surface bound protonated-MBI species $\left(\mathrm{MBIH}^{+}\right)$; recent $\mathrm{UV}-\mathrm{Vis}$ data indicate that $\mathrm{MBIH}^{+}$is not 
apparent in bulk aqueous solution even at $\mathrm{pH} \sim 0$ [32]. Alternatively, a minor substrate component or some small amount of solution contamination are also possible origins of the $\mathrm{N}^{3}$ feature. It should be noted that the foregoing discussion on peak assignments does not take into account the possibility of core level shifts induced by surface bonding.

It should be noted that $\mathrm{C} 1 \mathrm{~s}$ and $\mathrm{S} 2 \mathrm{p}$ core level XPS spectra are not discussed here, as their interpretation in terms of MBI adsorption is not entirely transparent due to non-MBI related features; these spectra can be found in Supplementary Data. As regards C, the additional signal derives from the ubiquitous topmost layer of adventitious carbon [24,33], which forms during transfer of the sample to the XPS instrument. For S, the carbon-steel substrate contains $\mathrm{S}$ in inclusions, which is apparent in XPS subsequent to solution immersion.

To elucidate the surface termination of the carbon-steel, $\mathrm{O} 1 \mathrm{~s}, \mathrm{Fe} 2 \mathrm{p}$, and $\mathrm{Cl} 2 \mathrm{p}$ core level spectra need to be considered. Focussing on the $\mathrm{O} 1 \mathrm{~s}$ data (Figure 2 (b)), as expected [24], the polished sample exhibits four discrete peaks. The two lower BE features can be attributed to the presence of a surface film composed of iron oxide $\left(\mathrm{O}^{2-}, \mathrm{BE} \sim 530 \mathrm{eV}\right)$ and hydroxide $\left(\mathrm{OH}^{-}, \mathrm{BE} \sim 531.3\right.$ $\mathrm{eV})$ phases. As to the origin of the other two peaks $\left(\mathrm{O}^{1}, \mathrm{BE} \sim 532.2 \mathrm{eV}\right.$ and $\left.\mathrm{O}^{2}, \mathrm{BE} \sim 533.3 \mathrm{eV}\right)$, they are most likely due to adsorbed $\mathrm{OH}\left(\mathrm{O}^{1}\right)$ and $\mathrm{RC}_{\mathrm{x}} \mathrm{O}_{\mathrm{y}}\left(\mathrm{O}^{1}\right.$ and $\left.\mathrm{O}^{2}\right)$ species; the latter are components of the adventitious carbon layer [24]. It should be noted that some studies (e.g. [34]) suggest that a feature at $\mathrm{BE} \sim 533 \mathrm{eV}\left(\mathrm{O}^{2}\right)$ arises from adsorbed $\mathrm{H}_{2} \mathrm{O}$. In our opinion, such an assignment is inappropriate here, as temperature programmed desorption (TPD) data acquired in UHV (i.e. similar conditions to those of the XPS measurements) from both metallic iron and iron oxides suggest that no molecular water should be present on carbon-steel at room temperature in UHV [35-38]. Immersion in $1 \mathrm{M} \mathrm{HCl}$ leads to the complete quenching of the $\mathrm{O}^{2-}$ and $\mathrm{OH}^{-}$components. This phenomenon is attributed to dissolution of the surface iron oxide/hydroxide film, which remains absent as the concentration of MBI increases, suggesting that the inhibitor is adsorbed on an oxide/hydroxide free surface. 
Turning to the Fe 2p spectra (Figure 2 (c)), mirroring the corresponding $\mathrm{O} 1 \mathrm{~s}$ spectrum, the profile for the polished sample is consistent with the presence of a surface iron oxide/hydroxide film atop the carbon-steel substrate, i.e. features due to $\mathrm{Fe}^{3+/ 2+}$, and metallic $\mathrm{Fe}\left(\mathrm{Fe}^{0}\right)$ are observed. $\mathrm{Fe}^{3+}$ features persist for samples immersed in $1 \mathrm{M} \mathrm{HCl}$ with either $0 \mathrm{mM}$ or $0.005 \mathrm{mM}$ $\mathrm{MBI}$ added, although their intensity is reduced relative to the $\mathrm{Fe}^{0}$ signal. Given that there is no surface iron oxide/hydroxide film under these conditions, this $\mathrm{Fe}^{3+}$ must have some other origin. The significant intensity of the $\mathrm{Cl} 2 \mathrm{p}$ signal (Figure $2(\mathrm{~d})$ ) provides a possible answer, suggesting that the iron oxide/hydroxide film is replaced by a salt film of ferric chloride. Such an assignment is supported by the similarity of the current $\mathrm{Fe}^{3+}$ components with Fe $2 \mathrm{p}$ XPS data acquired from ferric chloride $\left(\mathrm{FeCl}_{3}\right)[39,40]$.

At higher MBI concentrations $(0.05 \mathrm{mM}$ and $2 \mathrm{mM})$, the $\mathrm{Cl} 2 \mathrm{p}$ signal (Figure $2(\mathrm{~d}))$ is greatly diminished, which can be ascribed to the absence of a chloride salt film under these conditions; the remnant $\mathrm{Cl} 2 \mathrm{p}$ signal arises from surface adsorbed $\mathrm{Cl}$ atoms. Confirming this change in substrate termination is the absence of $\mathrm{Fe}^{3+/ 2+}$ features in the $\mathrm{Fe} 2 \mathrm{p}$ spectra acquired from $1 \mathrm{M}$ $\mathrm{HCl}$ with either $0.05 \mathrm{mM}(\mathrm{IE}=94 \%)$ or $2 \mathrm{mM}(\mathrm{IE}=99 \%) \mathrm{MBI}$. Only a $\mathrm{Fe}^{0}$ peak is apparent, clearly demonstrating that for significantly inhibited carbon-steel substrate, there is no interfacial oxidic or chloride salt film facilitating MBI adsorption.

To further confirm that the MBI is bound directly to film-free carbon-steel, more surface sensitive Fe $2 p$ core level XPS spectra have been acquired by increasing the photoelectron emission angle, $\left(\theta_{\mathrm{E}}\right)$ from $0^{\circ}$ (emission along the surface normal) to $50^{\circ}$. In the latter measurement geometry any surface features would exhibit greater intensity, and so should be more apparent relative to bulk signal [41]. Inspection of the $\theta_{\mathrm{E}}=0^{\circ}$ and $\theta_{\mathrm{E}}=50^{\circ} \mathrm{Fe} 2 \mathrm{p}$ spectra recorded following immersion in $1 \mathrm{M} \mathrm{HCl}$ with either $0.05 \mathrm{mM}$ or $2 \mathrm{mM} \mathrm{MBI}$ (Figure 4) provide no evidence for surface features; the profiles of the normalised spectra are identical. This result 
supports our conclusion that for significantly inhibited carbon-steel, MBI is adsorbed onto filmfree substrate.

Concerning recent studies [8-10] that report organic-CI binding is mediated by a surface film, one possible reason for these apparently contradictory results is that simply the nature of the interface is highly dependent on the identity of the organic corrosion inhibitor. For example, as reported previously for docosanethiol on silver [42], the - SH group in MBI may be responsible for the reduced (film-free) carbon-steel surface in the current study. Alternatively, it may be that XPS data in the other studies were influenced by sample handling procedures. More specifically, exposure of the substrate to the ambient laboratory atmosphere, which was normally avoided in this study (a $\mathrm{N}_{2}$-glove box was employed), could have resulted in post immersion oxidation. Figure 5 demonstrates that such a phenomenon does indeed occur for the MBI/carbon-steel interface studied here. Fe $2 \mathrm{p}$ and $\mathrm{O}$ 1s core level spectra from substrates immersed in $1 \mathrm{M}$ $\mathrm{HCl}$ containing $2 \mathrm{mM} \mathrm{MBI}$, and exposed upon removal from solution to either $\mathrm{N}_{2}$ or the ambient laboratory atmosphere (sample was removed from solution into an incompletely $\mathbf{N}_{2}$-purged glove box) are displayed. There are clear differences in the spectral profiles, with features previously assigned to $\mathrm{Fe}^{2+/ 3+}$ and $\mathrm{O}^{2-} / \mathrm{OH}^{-}$being apparent on the inhibited substrate exposed to the ambient laboratory atmosphere, i.e. atmospheric $\mathrm{O}_{2}$ induces post immersion oxidation. We note that not only does the possibility of this adverse process have implications for future rigorous organic-CI/substrate interface characterisation, but it should also inform researchers undertaking analogous work in other areas where reliable solid/liquid interface descriptions are paramount to advancing technical performance.

Further to determining substrate termination as a function of MBI concentration, the surface coverage of MBI has been estimated. This quantification has been achieved through application of expressions derived from standard equations [41] to fit XPS intensity ratios $(\mathrm{N} \mathrm{1s}, \mathrm{C} 1 \mathrm{~s}$, and Fe $2 p)$ at both $\theta_{\mathrm{E}}=0^{\circ}$ and $\theta_{\mathrm{E}}=50^{\circ}$. For this work, it was assumed that the surface region 
consists of a topmost layer of adventitious carbon [33], a 2D layer of MBI (i.e. one molecule thick), and the carbon-steel substrate; surface coverage was only calculated for MBI concentrations where no surface film (oxide or chloride) was present, i.e. $\geq 0.05 \mathrm{mM}$. Figure 1 displays a plot of MBI surface coverage (blue markers) along with the inhibition efficiency data (red markers) as a function of MBI concentration in bulk solution. In line with expectation [1,2], the two plots display similar trends. Interestingly, however, inhibition efficiency more rapidly approaches a maximum than MBI surface coverage, suggesting that active surface sites for corrosion are preferential locations for MBI binding.

\section{Conclusions}

Summarising the conclusions drawn from the XPS data, Figure 6 provides a schematic illustration of the carbon-steel substrate termination as a function of environment. The polished sample exhibits an iron oxide/hydroxide film, which dissolves upon immersion in $1 \mathrm{M} \mathrm{HCl}$, being replaced by an iron chloride salt film. In the presence of sufficient MBI to significantly inhibit substrate corrosion, this salt film is no longer present and the MBI binds to film-free carbon-steel substrate. Such interface characterisation could contribute towards knowledge-based efforts to improve CI performance. For example, this information can direct those trying to improve the performance of candidate organic CI species through theoretical modeling to undertake their work on relevant interfaces. Furthermore, the data demonstrate the importance of correct sample handling procedures prior to acquisition of XPS spectra, i.e. exposure to the ambient laboratory atmosphere may lead to interfacial modification, leading to erroneous mechanistic understanding. 


\section{Acknowledgements}

PMG is grateful to the Fondo Sectorial CONACYT - SENER Hidrocarburos and the Instituto Mexicano de Petróleo for financial support. MSW also acknowledges funding from the Instituto Mexicano de Petróleo. 


\section{References}

1. V.S. Sastri, Corrosion Inhibitors Principles and Applications, Wiley, Chichester, 1998.

2. R. Lindsay, S.B. Lyon, Introduction to Control of Corrosion by Environmental Control, in: R. A. Cottis et al. (Eds.), Shreir's Corrosion, Vol. 4, Management and Control of Corrosion, Elsevier, Amsterdam, 2010, pp. 2891-2899.

3. E.E. Oguzie, S.G. Wang, Y. Li, F. H. Wang, Influence of Iron Microstructure on Corrosion Inhibitor Performance in Acidic Media, J. Phys. Chem. C 113 (2009) 84208429.

4. G. Bhargava, T.A. Ramanarayanan, S.L. Bernasek, Imidazole-Fe Interaction in an Aqueous Chloride Medium: Effect of Cathodic Reduction of the Native Oxide, Langmuir 26 (2010) 215-219.

5. A. Kokalj, S. Peljhan, M. Finšgar, I. Milošev, What Determines the Inhibition Effectiveness of ATA, BTAH, and BTAOH Corrosion Inhibitors on Copper?, J. Am. Chem. Soc. 132 (2010) 16657-16668.

6. E.E. Oguzie, Y. Li, S.G. Wang, F. Wang, Understanding corrosion inhibition mechanisms - experimental and theoretical approach, RSC Adv. 1 (2011) 866-873.

7. J.O. Mendes, E.C. da Silva, A.B. Rocha, On the nature of inhibition performance of imidazole on iron surface, Corros. Sci. 57 (2012) 254-259.

8. O. Olivares-Xometl, N.V. Likhanova, R. Martínez-Palou, M.A. Domínguez-Aguilar, Electrochemistry and XPS study of an imidazoline as corrosion inhibitor of mild steel in an acidic environment, Mater. Corros. 60 (2009) 14-21. 
9. E.A. Flores, O. Olivares, N.V. Likhanova, M.A. Domínguez-Aguilar, N. Nava, D. Guzman-Lucero, M. Corrales, Sodium phthalamates as corrosion inhibitors for carbon steel in aqueous hydrochloric acid solution, Corros. Sci. 53 (2011) 3899-3913.

10. H. Zarrok, A. Zarrouk, B. Hammouti, R. Salghi, C. Jama, F. Bentiss, Corrosion control of carbon steel in phosphoric acid by purpald - Weight loss, electrochemical and XPS studies, Corros. Sci. 64 (2012) 243-252.

11. G. Gece, The use of quantum chemical methods in corrosion inhibitor studies, Corros. Sci. 50 (2008) 2981-2992.

12. P.M. Niamien, F.K. Essy, A. Trokourey, A. Yapi, H.K. Aka, D. Diabate, Correlation between molecular structure and the inhibiting effect of some benzimidazole derivatives, Mater. Chem. Phys. 136 (2012) 59-65.

13. L. Li, X. Zhang, J. Lei, J. He, S. Zhang, F. Pan, Adsorption and corrosion inhibition of Osmanthus fragran leaves extract on carbon steel, Corros. Sci. 63 (2012) 82-90.

14. N. Kovačević, A. Kokalj, DFT Study of Interaction of Azoles with $\mathrm{Cu}(111)$ and $\mathrm{Al}(111)$ surfaces: Role of Nitrogen Atoms and Dipole-Dipole interactions, J. Phys. Chem. C 115 (2011) 24189-24197.

15. X. Chen, H. Häkkinen, Divide and Protect: Passivating $\mathrm{Cu}(111)$ by $\mathrm{Cu}-(\text { benzotriazole) })_{2}$, J. Phys. Chem. C 116 (2012) 22346-22349.

16. A. Popova, M. Christov, S. Raicheva, E. Sokolova, Adsorption and inhibitive properties of benzimidazole derivatives in acid mild steel corrosion, Corros. Sci. 46 (2004) 13331350. 
17. P. Morales-Gil, G. Negrón-Silva, M. Romero-Romo, C. Ángeles-Chávez, M. PalomarPardavé, Corrosion inhibition of pipeline steel grade API 5L X52 immersed in a $1 \mathrm{M}$ $\mathrm{H}_{2} \mathrm{SO}_{4}$ aqueous solution using heterocyclic organic molecules, Electrochim. Acta 49 (2004) 4733-4741.

18. J. Aljourani, K. Raeissi, M.A. Golozar, Benzimidazole and its derivatives as corrosion inhibitors for mild steel in 1M HCl solution, Corros. Sci. 51 (2009) 1836-1843.

19. R. Álvarez-Bustamante, G. Negrón-Silva, M. Abreu-Quijano, H. Herrera-Hernández, M. Romero-Romo, A. Cuán, M. Palomar-Pardavé, Electrochemical study of 2mercaptoimidazole as a novel corrosion inhibitor for steels, Electrochim. Acta 54 (2009) 5393-5399.

20. M. Mahdavian, S. Ashhari, Corrosion inhibition performance of 2mercaptobenzimidazole and 2-mercaptobenzoxazole compounds for protection of mild steel in hydrochloric acid solution, Electrochim. Acta. 55 (2010) 1720-1724.

21. J. Aljourani, M.A. Golozar, K. Raeissi, The inhibition of carbon steel corrosion in hydrochloric and sulfuric acid media using some benzimidazole derivatives. Mater. Chem. Phys. 121 (2010) 320-325.

22. M. Benabdellah, A. Tounsi, K.F. Khaled, B. Hammouti, Thermodynamic, chemical and electrochemical investigations of 2-mercaptobenzimidazole as corrosion inhibitor for mild steel in hydrochloric acid solutions, Arab. J. Chem. 4 (2011) 17-24.

23. R.A. Cottis, Electrochemical Methods, in: R. A. Cottis et al. (Eds.), Shreir's Corrosion, Vol. 2, Corrosion in Liquids, Corrosion Evaluation, Elsevier, Amsterdam, 2010, pp. 1341-1373. 
24. A.A. Al-Refaie, J. Walton, R.A. Cottis, R. Lindsay, Photoelectron spectroscopy of the inhibition of mild steel corrosion by molybdate and nitrite anions, Corros. Sci. 52 (2010) $422-428$

25. Casa Software Ltd., Teignmouth, Devon, UK. www.casaxps.com.

26. R.P. Gupta, S.K. Sen, Calculation of multiplet structure of core $p$-vacancy levels. II, Phys. Rev. B 12 (1975) 15-19.

27. D.A. Shirley, High-Resolution X-ray Photoemission Spectrum of the Valence Bands of Gold, Phys. Rev. B 5 (1972) 4709-4714.

28. T. Yoshida, K. Yamasaki, S. Sawada, An X-ray Photoelectron Spectroscopic Study of 2Mercaptobenzothiazole Metal Complexes. Bull. Chem. Soc. Jpn. 52 (1979) 2908 - 2912.

29. C.M. Whelan, M.R. Smyth, C.J. Barnes, N.M.D. Brown, C.A. Anderson, An XPS study of heterocyclic thiol self-assembly on Au(111), Appl. Surf. Sci. 134 (1998) 144 - 158.

30. M. Finšgar, 2-Mercaptobenzimidazole as a copper corrosion inhibitor: Part II. Surface analysis using X-ray photoelectron spectroscopy, Corros. Sci. 72 (2013) 90 - 98.

31. J.S. Stevens, S.J. Byard, C.C. Seaton, G. Sadiq, R.J. Davey, S.L.M. Schroeder, Crystallography aided by atomic core-level binding energies: proton transfer versus hydrogen bonding in organic crystal structures, Angew. Chem. Int. Ed. 50 (2011) 9916.

32. S. Ansar, R. Haputhanthri, B. Edmonds, D. Liu, L. Yu, A. Sygula, D. Zhang, Determination of binding affinitiy, packing and conformation of thiolate an thione ligands on gold nanoparticles, J. Phys. Chem. C 115 (2011) 653-660. 
33. G.C. Smith, Evaluation of simple correction for the hydrocarbon contamination layer in quantitative surface analysis by XPS, J. Electron Spectrosc. Rel. Phenom. 148 (2005) 2128.

34. M. Mullet, Y. Guillemin, C. Ruby, Oxidation and deprotonation of synthetic $\mathrm{Fe}^{\mathrm{II}}-\mathrm{Fe}^{\mathrm{III}}$ (oxy)hydroxycarbonate Green Rust: An X-ray photoelectron study, J. Sol. Stat. Chem. $181(2008) 81-89$.

35. W.-H. Hung, J. Schwartz, S.L. Bernasek, Sequential oxidation of Fe(100) by water adsorption: formation of an ordered hydroxylated surface, Surf. Sci. 248 (1991) 332-342.

36. C. Ruby, J. Fusy, M. Alnot, J.-M. Génin, J.-J. Ehrhardt, Structural properties and water adsorption behaviour of iron films grown on $\mathrm{Cu}(111)$, Thin Solid Films 311 (1997) 4450.

37. M.A. Henderson, S.A. Joyce, J.R. Rustad, Interaction of water with the (1x1) and (1x2) surfaces of $\alpha-\mathrm{Fe}_{2} \mathrm{O}_{3}(012)$, Surf. Sci. 417 (1998) 66-81.

38. U. Leist, W. Ranke, K. Al-Shamery, Water adsorption and growth of ice on epitaxial $\mathrm{Fe}_{3} \mathrm{O}_{4}(111), \mathrm{FeO}(111)$ and $\mathrm{Fe}_{2} \mathrm{O}_{3}$ (biphase), Phys. Chem. Chem. Phys. 5 (2003) 24352441.

39. A.P. Grosvenor, B.A. Kobe, M.C. Biesinger, N.S. McIntyre, Invesitgation of multiplet splitting of Fe 2p XPS spectra and bonding in iron compounds, Surf. Interface Anal. 36 (2004) 1564-1574.

40. A.P. Grosvenor, private communication.

41. Fadley, C. S. Angle-resolved X-ray Photoelectron Spectroscopy, Prog. Surf. Sci. 16 (1984) 275-388. 
42. M. Himmelhaus, I. Gauss, M. Buck, F. Eisert, Ch. Wöll, M. Grune, Adsorption of docosanethiol from solution on polycrystalline silver surfaces: an XPS and NEXAFS study, J. Electron Spectrosc. Relat. Phenom. 92 (1998) 139-149. 


\section{Figure Captions}

Figure 1 Inhibition efficiency (red markers) and MBI surface coverage (blue markers) as a function of MBI concentration in bulk solution for carbon-steel after $4 \mathrm{hr}$ of immersion in $1 \mathrm{M} \mathrm{HCl}$. Each value of inhibition efficiency has been calculated on the basis of two or more corrosion rate determinations (different samples) at each concentration of $\mathrm{MBI}(0 \mathrm{mM}-2 \mathrm{mM})$; error bars indicate the associated standard deviation. Displayed errors in MBI surface coverage have been derived from the uncertainty in the intensity of core level peaks. Inset shows the same data but on a log-log plot. Dashed lines act as guides for the eye.

Figure 2 High-resolution XPS spectra of selected core levels: (a) N 1s, (b) O 1s, (c) Fe 2p, and (d) $\mathrm{Cl} 2 \mathrm{p}$. In each panel, data acquired from polished carbon-steel, and subsequent to immersion in $1 \mathrm{M} \mathrm{HCl}$ containing various concentrations of $\mathrm{MBI}(0$ $\mathrm{mM}-2 \mathrm{mM}$ ) are presented. Also displayed are the best fits (light blue markers) to the experimental data (solid black lines), achieved with a combination of GL (red lines), LF (red lines), and Shirley-type (broken grey lines) functions.

Figure 3 Thiol and thione tautomers of MBI, with the chemically distinct $\mathrm{N}$ atoms labelled $\mathrm{N}^{1}$ (pyridine-like) and $\mathrm{N}^{2}$ (pyrrole-like).

Figure 4 Fe $2 p$ core level XPS spectra acquired at $\theta_{\mathrm{E}}=0^{\circ}$ (solid black lines) and $\theta_{\mathrm{E}}=50^{\circ}$ (broken red lines). Data acquired from polished carbon-steel, and subsequent to 
immersion in $1 \mathrm{M} \mathrm{HCl}$ containing various concentrations of $\mathrm{MBI}(0 \mathrm{mM}-2 \mathrm{mM})$ are displayed. All of the spectra have been normalised to have a maximum (minimum) intensity of $1(0)$.

Figure 5 High-resolution XPS spectra of (a) Fe 2p and (b) $\mathrm{O}$ 1s core levels. Data were acquired from carbon-steel samples subsequent to $4 \mathrm{~h}$ of immersion in $1 \mathrm{M}$ HCl containing $2 \mathrm{mM}$ of MBI. In each panel, the lower (upper) spectrum is from a sample exposed to $\mathrm{N}_{2}$ (ambient laboratory atmosphere) upon removal from solution.

Figure 6. Cartoon illustrating carbon-steel termination as a function of environment. The conditions under which these terminations are exhibited are detailed below each illustration. It should be noted that on the basis of the experimental data presented, details of the morphology of the iron chloride film cannot be determined with any certainty. For example, this film may only exist in discrete areas (patches) on top of the carbon-steel substrate. 


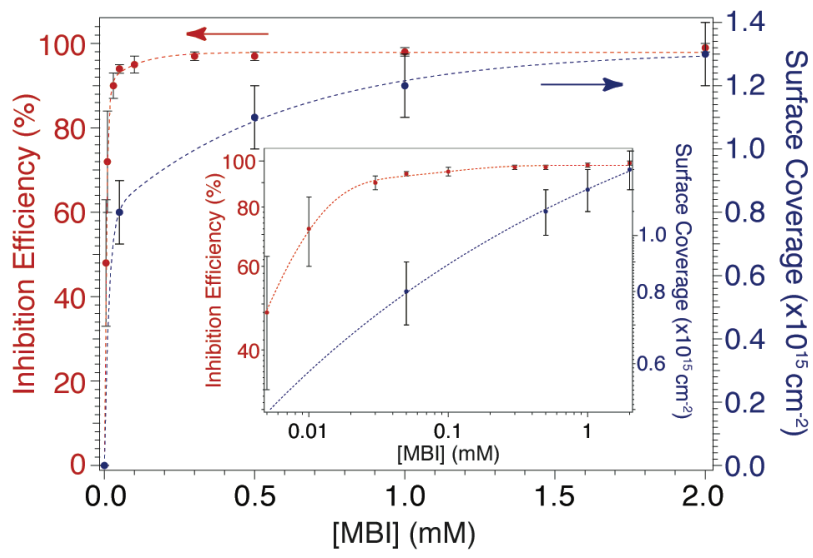

Figure 1 

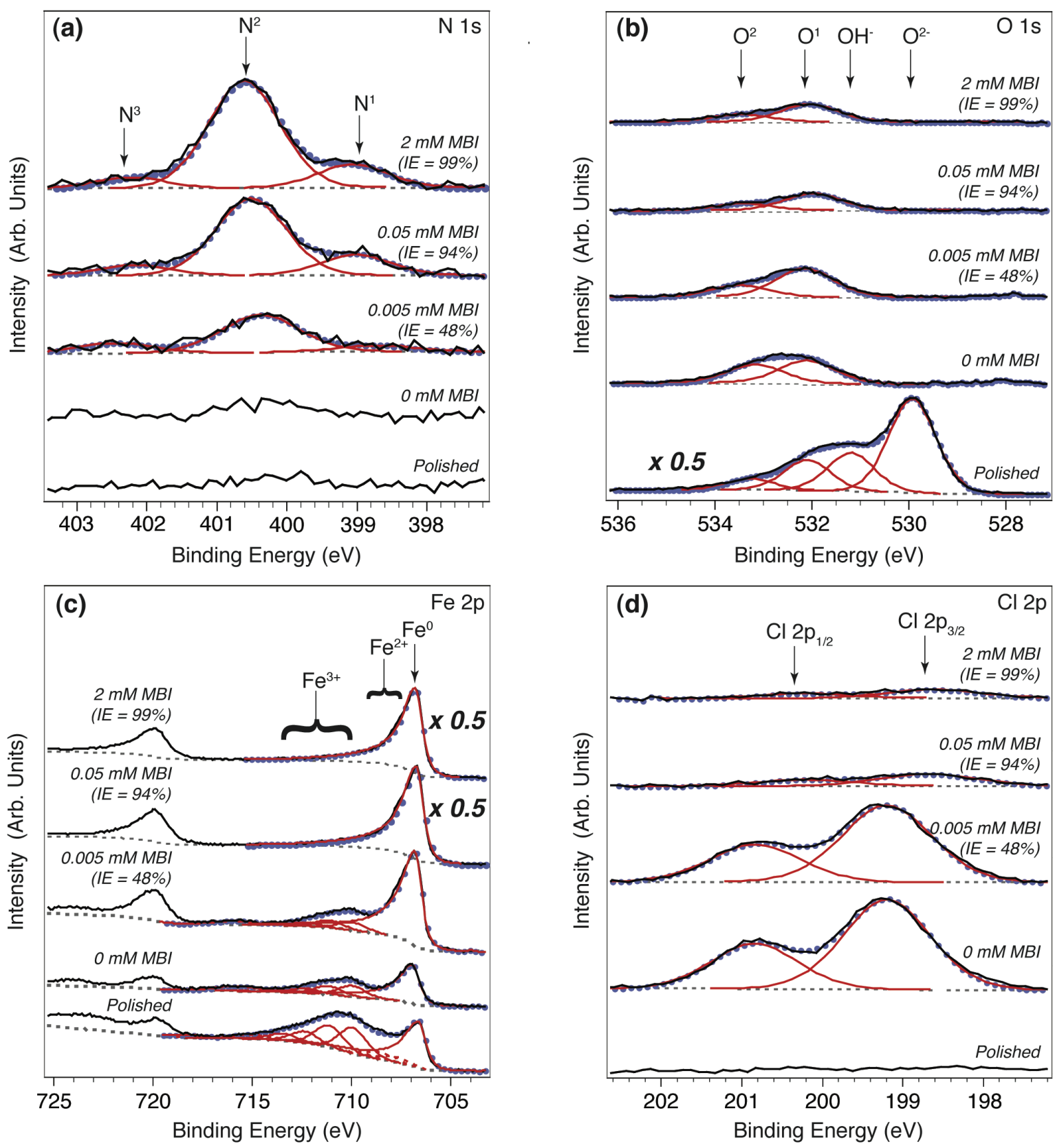

Figure 2 


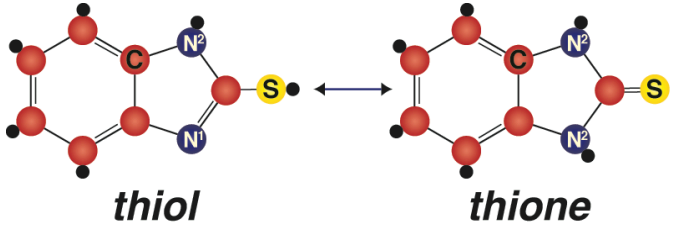

Figure 3 


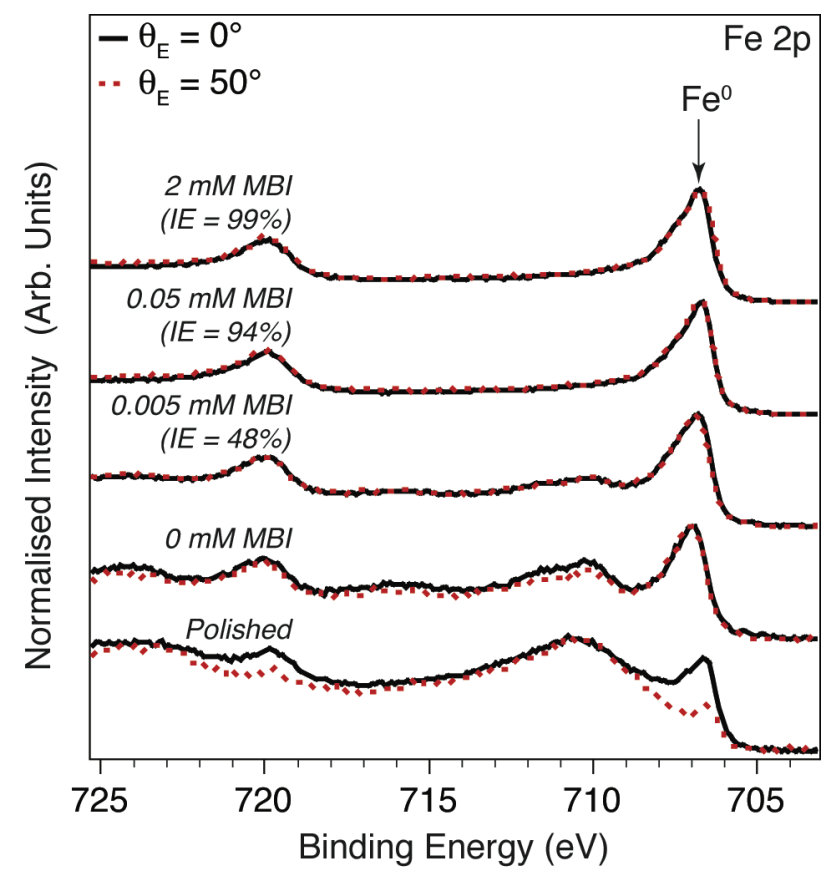

Figure 4 

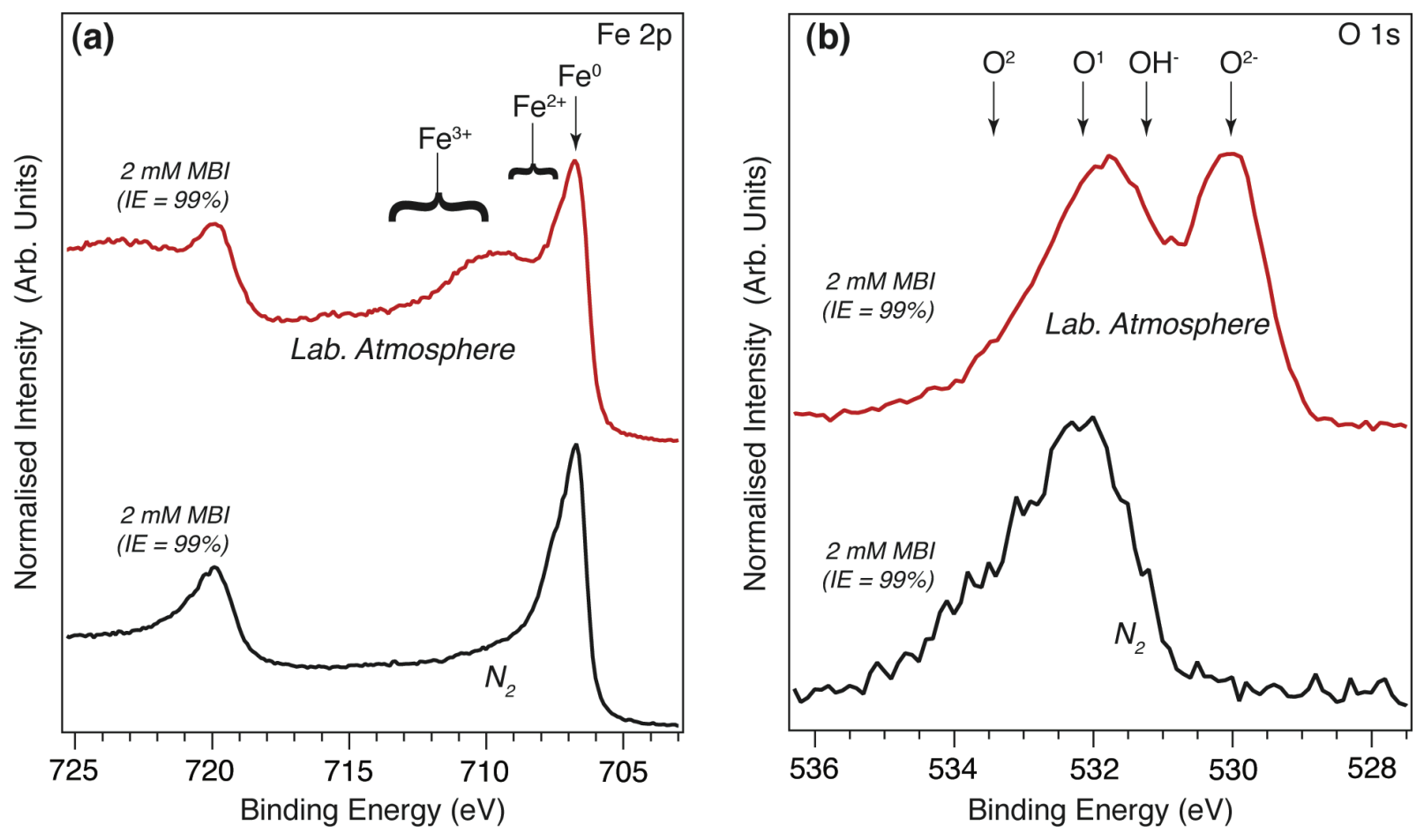

Figure 5 


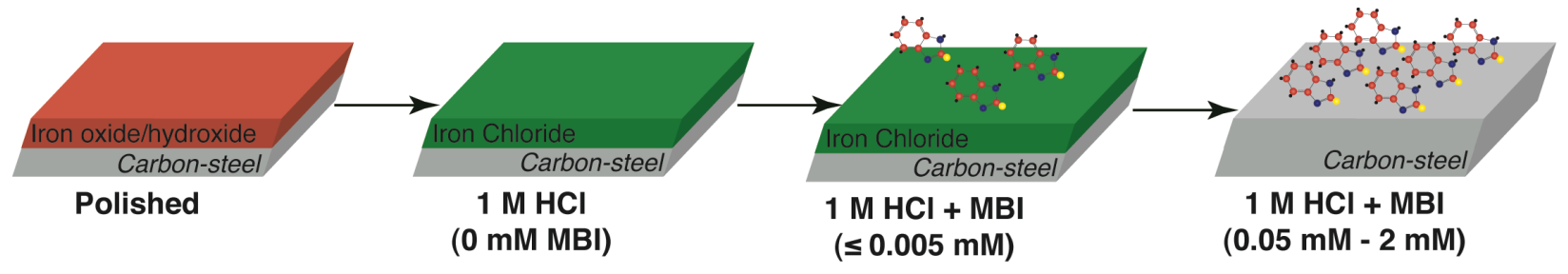

Figure 6 